\title{
5-Aminolevulinic acid strongly enhances delayed intracellular production of reactive oxygen species (ROS) generated by ionizing irradiation: Quantitative analyses and visualization of intracellular ROS production in glioma cells in vitro
}

\author{
TAKEHIRO KITAGAWA ${ }^{1}$, JUNKOH YAMAMOTO ${ }^{1}$, TOHRU TANAKA ${ }^{2}$, YOSHITERU NAKANO $^{1}$, \\ DAISUKE AKIBA $^{1}$, KUNIHIRO UETA ${ }^{1}$ and SHIGERU NISHIZAWA ${ }^{1}$ \\ ${ }^{1}$ Department of Neurosurgery, University of Occupational and Environmental Health, Kitakyushu, Fukuoka; \\ ${ }^{2}$ SBI Pharmaceuticals Co., Ltd., Minato-ku, Tokyo, Japan
}

Received July 9, 2014; Accepted October 17, 2014

DOI: $10.3892 /$ or.2014.3618

\begin{abstract}
Postoperative adjuvant radiotherapy has important roles in multimodal treatment for highly aggressive malignant gliomas. Previously, we demonstrated that multi-dose ionizing irradiation with repetitive administration of 5-aminolevulinic acid (5-ALA) enhanced the host antitumor response and strongly inhibited tumor growth in experimental glioma. However, the mechanism of the radiosensitizing effect of 5-ALA is not known. Ionizing irradiation not only causes reactive oxygen species (ROS) formation initially by water radiolysis but also induces delayed production of mitochondrial ROS for mediating the long-lasting effects of ionizing irradiation on tumor cells. 5-ALA leads to high accumulation of protoporphyrin IX (PpIX) in the mitochondria of tumor cells, yet can also improve dysfunction of the mitochondrial respiratory chain in tumor cells. Here, we assessed the effect of 5-ALA-induced PpIX synthesis and delayed production of intracellular ROS after ionizing irradiation with 5-ALA in glioma cells in vitro. Temporal changes in intracellular 5-ALA-induced PpIX synthesis after ionizing irradiation in glioma cell lines were evaluated using flow cytometry (FCM). Then, the effect of 5-ALA on delayed production of intracellular ROS $12 \mathrm{~h}$ after ionizing irradiation in glioma cells was evaluated by FCM and confocal laser scanning microscopy. Ionizing irradiation had no effect on 5-ALA-induced PpIX synthesis in glioma cells. Delayed intracellular production of ROS was significantly higher than that just after ionizing
\end{abstract}

Correspondence to: Dr Junkoh Yamamoto, Department of Neurosurgery, University of Occupational and Environmental Health, 1-1 Iseigaoka, Yahatanishi-ku, Kitakyushu, Fukuoka 807-8555, Japan E-mail: yama9218@med.uoeh-u.ac.jp

Key words: 5-aminolevulinic acid, radiosensitizer, radiotherapy, glioma, reactive oxygen species, cancer, mitochondria irradiation, but 5-ALA pretreatment strongly enhanced the delayed intracellular production of ROS, mainly in the cytoplasm of glioma cells. This 5-ALA-induced increase in the delayed production of ROS tended to be higher in the case of 5-ALA treatment before rather than after ionizing irradiation. These results suggest that 5-ALA can affect tumor cells under ionizing irradiation, and greatly increase secondary intracellular production of ROS long after ionizing irradiation, thereby causing a radiosensitizing effect in glioma cells.

\section{Introduction}

Malignant gliomas are highly aggressive and locally invasive brain tumors that have an extremely poor prognosis despite the various types and intensity of treatment available. Mean survival time in patients with glioblastoma is about 12-14 months $(1,2)$. In the multimodal treatment of glioblastoma, cytoreductive surgery is crucial. Studies suggest that the extent of resection (starting from $78 \%$ and increasing to almost $100 \%$ of contrast-enhanced tumor volume) improves the overall survival of patients with glioblastoma $(3,4)$.

5-Aminolevulinic acid (ALA) induces a high accumulation of protoporphyrin IX (PpIX) in tumors, and is widely used in the treatment of various types of cancers $(5,6)$. In the treatment of malignant gliomas, fluorescence-guided surgery using 5-ALA has been useful for determining tumor borders, thereby making the extent of resection easier compared to that in conventional microsurgery (7). Thus, 5-ALA fluorescence-guided surgery for malignant gliomas is a very practical and simple method for neurosurgeons. The extent of resection of malignant gliomas in deep and eloquent regions for the avoidance of postoperative neurological deficit is limited even though the 'fluorescent' tumor remains visible $(8,9)$. In addition, the recurrence rate of malignant gliomas despite aggressive resection is virtually $100 \%$ (10). Therefore, postoperative adjuvant radiotherapy is highly recommended for managing residual tumors in malignant gliomas (11).

Photodynamic therapy (PDT) using photosensitizers such as hematoporphyrin derivatives (HpD), photofrin and 
5-ALA, is effective in several types of cancers (12-14). These porphyrin compounds of $\mathrm{HpD}$ and photofrin have been shown to act as radiosensitizers, yet the radiosensitizing effect of 5-ALA is controversial (15-17). Previously, we showed that the radiosensitizing effect of 5-ALA via single-dose ionizing irradiation is weak, yet multi-dose ionizing radiation can enhance host antitumor response and strongly inhibit tumor growth in experimental gliomas in vivo $(18,19)$.

The mechanism of the radiosensitizing effect of 5-ALA is not clear. In general, ionizing irradiation initially causes the ionization and excitation of water. This leads to the formation of the products of water radiolysis with some reactive oxygen species (ROS; particularly hydroxyl radicals) in a very short period, which induces double-strand breaks in DNA $(20,21)$. Recent studies have reported that ionizing irradiation leads not only to the generation of ROS derived from water radiolysis, yet also leads to increases in the delayed production of intracellular ROS several hours after exposure to ionizing irradiation (22-24). This delayed ROS production is induced primarily in the mitochondria of tumor cells $(24,25)$. Meanwhile, the heme precursor 5-ALA presents not only a high accumulation of PpIX in the mitochondria of tumor cells, but also improves dysfunction of the mitochondrial respiratory chain in tumor cells (26-28). Thus, we hypothesized that 5-ALA-induced PpIX may operate upon mitochondria, and cause changes in delayed production of ROS after ionizing irradiation in tumor cells.

In the present study, we assessed the effect of the synthesis of 5-ALA-induced PpIX and delayed production of intracellular ROS after exposure to ionizing irradiation with 5-ALA in glioma cells using flow cytometric analyses in vitro. The subcellular localization of intracellular ROS generated by this combined treatment was evaluated in glioma cells using confocal laser scanning microscopy. We also discussed the possible mechanism of the radiosensitizing effect of 5-ALA in malignant gliomas.

\section{Materials and methods}

Chemicals.5-ALA was purchased from Cosmobio(K.K.,Tokyo, Japan) and dissolved in fresh culture medium at a final concentration of $1 \mathrm{mM}$ for the in vitro study. 2',7'-Dichlorofluorescein diacetate (DCFD) was purchased from Sigma-Aldrich (K.K., Tokyo, Japan). DCFD was dissolved in fresh culture medium or phosphate-buffered saline (PBS)/fetal bovine serum (FBS) at a final concentration of $10 \mu \mathrm{M}$. Other materials were of the highest grade available.

Culture and treatment of cells. Two rat glioma cell lines (9L and C6) and two human glioma cell lines (U251 and T98G) were used. 9L and T98G cells were cultured for several days in RPMI-1640, and C6 and U251 in Dulbecco's modified Eagle's medium (DMEM) with $10 \% \mathrm{FBS}$ at $37^{\circ} \mathrm{C}$ before use, respectively. These cell lines were maintained in a humidified incubator with $5 \% \mathrm{CO}_{2}$ at $37^{\circ} \mathrm{C}$. Cells were passaged in the exponential growing phase using a $0.05 \%$ trypsin solution containing $0.5 \mathrm{mM}$ ethylenediaminetetraacetic acid. Cells at $70 \%$ confluency were used in the subsequent experiments. 5-ALA was dissolved in RPMI-1640 (9L and T98G) or DMEM (C6 and U251) with 10\% FBS to achieve a final concentration of $1 \mathrm{mM}$. This concentration of 5-ALA was used in the subsequent experiments.

Evaluation of intracellular levels of 5-ALA-induced PpIX in glioma cells using flow cytometric analyses. Cells were seeded in 100-mm culture dishes and cultured. Cells in the 5-ALA group were incubated in complete medium containing $1 \mathrm{mM}$ 5-ALA for $4 \mathrm{~h}$, and then washed with PBS. Cells were detached from the substratum by trypsinization and collected by centrifugation ( $400 \mathrm{x}$ g for $3 \mathrm{~min}$ at $4^{\circ} \mathrm{C}$ ). Immediately afterwards, cells were resuspended in cold PBS/FBS, and analyzed using a flow cytometer (EC800; Sony Biotechnology, Tokyo, Japan). Overall, 30,000 cells in each sample were evaluated. Fluorescence from intracellular PpIX was excited by an argon ion laser line at $488 \mathrm{~nm}$, and fluorescence were detected using a 640/30 nm band-pass filter. All procedures were carried out in the dark to avoid photoactivation of 5-ALA-induced PpIX. Analyses of flow cytometric data were carried out using FlowJo (Tree Star Inc., Ashland, OR, USA). The median fluorescence intensity (MFI) of PpIX fluorescence in the cells treated with 5-ALA in relation to that of cells that did not undergo 5-ALA treatment was calculated for each cell line.

Evaluation of intracellular levels of ROS after ionizing irradiation in glioma cells. Intracellular production of ROS was assessed using an oxidant-sensitive fluorescent probe DCFD with a flow cytometer (25). Cells were seeded in $100-\mathrm{mm}$ culture dishes, and then irradiated with $10 \mathrm{~Gy}$ in the dark using an X-ray irradiator (MBR-1520R; Hitachi, Tokyo, Japan) at $0.67 \mathrm{~Gy} / \mathrm{min}$. During ionizing irradiation, culture dishes were kept in a dark container at room temperature. In the 5-ALA with ionizing irradiation (RT, $12 \mathrm{~h}+\mathrm{ALA}$ ) group, cells were treated with $1 \mathrm{mM} 5$-ALA for $4 \mathrm{~h}$, exposed immediately to ionizing irradiation, and incubated in the dark. Twelve hours after exposure to ionizing irradiation, cells were incubated with $10 \mu \mathrm{M}$ DCFD for $15 \mathrm{~min}$ at $37^{\circ} \mathrm{C}$, and washed twice with PBS. Then, DCFD fluorescence was analyzed using a flow cytometer (excitation, $488 \mathrm{~nm}$; emission, 525/50 $\mathrm{nm}$ band-pass filter) as described above. Control cells were not exposed to ionizing irradiation or 5-ALA. In the 5-ALA group, cells were treated with $1 \mathrm{mM} 5$-ALA for $4 \mathrm{~h}$ but not exposed to ionizing irradiation. Control cells and cells in the 5-ALA group were treated similarly with DCFD. All procedures were conducted in the dark to avoid photoactivation of 5-ALA-induced PpIX and DCFD. Analyses of flow cytometric data were carried out using FlowJo. The MFI of DCF fluorescence of cells in relation to that of the control cells was calculated for each cell line.

Detection of subcellular localization of ROS $12 \mathrm{~h}$ after ionizing irradiation in glioma cells in vitro. Intracellular production of ROS was detected using DCFD with a confocal laser scanning microscope (LMS5 Pascal; Carl Zeiss, Jena, Germany) according to our method (18). Briefly, cells were seeded into 35-mm glass-bottom dishes (Asahi Techno Glass, Tokyo, Japan) in fresh medium containing $1 \mathrm{mM}$ 5-ALA and incubated in the dark at $37^{\circ} \mathrm{C}$ for $4 \mathrm{~h}$. Cells were then washed with PBS and exposed to $10 \mathrm{~Gy}$ of ionizing irradiation. Twelve hours after ionizing irradiation, cells were washed twice with PBS and incubated with $10 \mu \mathrm{M}$ DCFD for $15 \mathrm{~min}$. Cells were washed twice with PBS and observed immediately. DCFD 

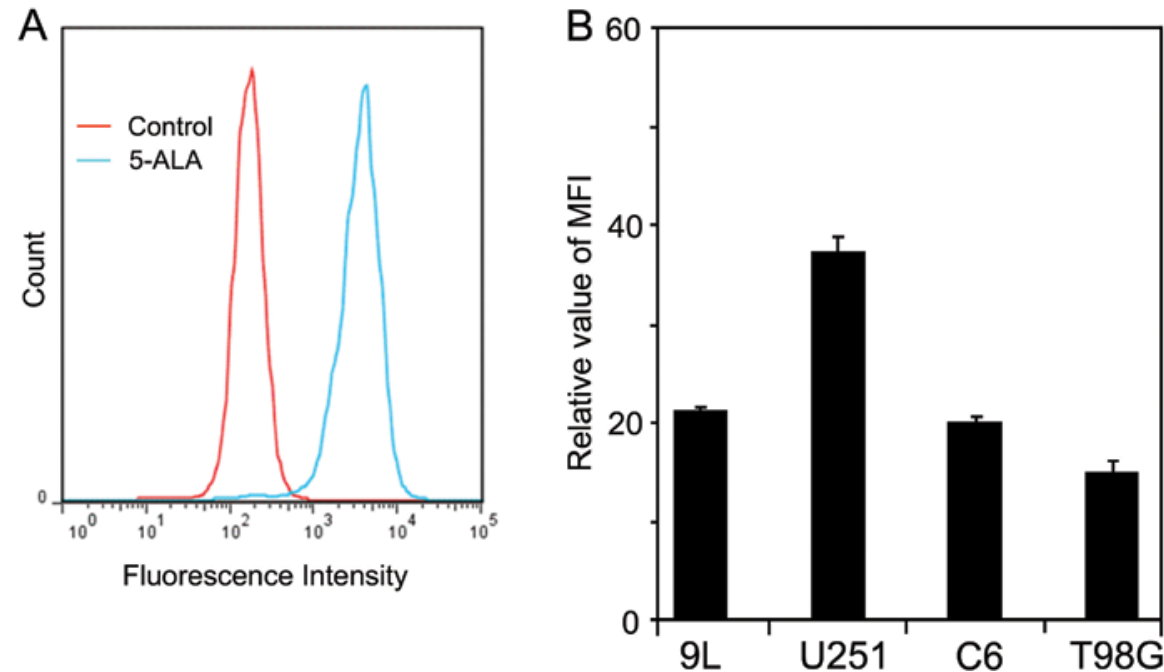

Figure 1. Intracellular PpIX fluorescence in glioma cells using flow cytometric analyses. Glioma cells were treated with $1 \mathrm{mM} 5$-ALA and incubated for $4 \mathrm{~h}$ The control involved no treatment with 5-ALA. (A) Representative flow cytometric profiles of PpIX fluorescence intensity in the 5-ALA-treated cells and the control in the 9L cells. (B) Relative MFI of 5-ALA-induced PpIX fluorescence compared with the control in the glioma cells. Columns, mean (n=3); bars, SE. PpIX, protoporphyrin IX; 5-ALA, 5-aminolevulinic acid; MFI, median fluorescence intensity.

fluorescence (excitation, $488 \mathrm{~nm}$; emission, 505-530-nm band-pass filter) was imaged on a confocal laser scanning microscope. All procedures were carried out in the dark.

Changes in delayed intracellular production of ROS after ionizing irradiation at different times of 5-ALA treatment in glioma cells. Cells were seeded in 100-mm culture dishes, and exposed to $10 \mathrm{~Gy}$ of ionizing irradiation. The incubation time of $1 \mathrm{mM}$ 5-ALA (4 h) was identical in each group, and three 5-ALA treatment times were initiated: i) 5-ALA treatment just before ionizing irradiation [RT+ALA (pre) group]; ii) 5-ALA treatment just after ionizing irradiation [RT+ALA (4 h) group]; iii) 5-ALA treatment $8 \mathrm{~h}$ after ionizing irradiation [RT+ALA $(12 \mathrm{~h})$ group]. Twelve hours after ionizing irradiation, cells were incubated with $10 \mu \mathrm{M}$ DCFD for $15 \mathrm{~min}$ at $37^{\circ} \mathrm{C}$, and washed twice with PBS in each group. Immediately afterwards, DCF fluorescence was analyzed using a flow cytometer as described above. Control cells were not treated with ionizing irradiation or 5-ALA. In the ionizing irradiation-only (RT) group, cells were exposed to ionizing irradiation without 5-ALA treatment, and similarly treated with DCFD $12 \mathrm{~h}$ after exposure to ionizing irradiation. All procedures were carried out in the dark. Analyses of flow cytometric data were conducted using FlowJo software. The MFI of DCF fluorescence in cells relative to that of the control cells was calculated in each cell line.

Statistical analyses. Data are means $\pm \mathrm{SE}$ and were analyzed with Fisher's protected least significant difference test; $p<0.05$ was considered to indicate a statistically significant result.

\section{Results}

Temporal changes in the synthesis of 5-ALA-induced PpIX after ionizing irradiation in glioma cells. We first examined intracellular accumulation of 5-ALA-induced PpIX using flow cytometric analyses in glioma cell lines. The MFI of PpIX fluorescence in the 5-ALA-treated cells was obviously increased compared with the control in each cell line (Fig. 1). The relative MFI of PpIX fluorescence (means \pm SE) was $21.5 \pm 0.12,37.6 \pm 0.12,20.2 \pm 0.56$ and $15.3 \pm 0.89$ in the 9L, U251, C6 and T98G cells, respectively. Among these cell lines, we selected two that showed a higher relative MFI value (9L and U251), and used them in the subsequent studies. Next, we confirmed the influence of ionizing irradiation on the production of 5-ALA-induced PpIX in the 9L and U251 cell lines (Fig. 2). In the 9L cells, the relative MFI of PpIX fluorescence (means \pm SE) 4, 12 and $24 \mathrm{~h}$ after ionizing irradiation was $15.2 \pm 0.15,15.9 \pm 0.73$ and $13.4 \pm 2.43$, respectively. There were no significant differences in each group (Fig. 2A). Similarly, in the U251 cells, the relative MFI of PpIX fluorescence (means \pm SE) 4,12 and $24 \mathrm{~h}$ after ionizing irradiation was $41.6 \pm 0.20,44.2 \pm 3.67$ and $51.1 \pm 3.76$, respectively. There were no significant differences in each group (Fig. 2B).

Delayed increases in intracellular levels of ROS after ionizing irradiation concurrent with 5-ALA treatment in glioma cells. Fig. 3 shows the temporal changes in intracellular production of ROS after ionizing irradiation in the 9L and U251 cells. To evaluate the direct interaction between 5-ALA-induced PpIX and ionizing irradiation in ROS production, cells were pretreated with 5-ALA just before exposure to ionizing irradiation (Fig. 3A). In the 9L cells, the relative MFI of DCF fluorescence in the 5-ALA without ionizing irradiation and just after ionizing irradiation growth without 5-ALA (RT $0 \mathrm{~h}$ ) (means $\pm \mathrm{SE}$ ) was $1.19 \pm 0.07$ and $1.04 \pm 0.07$, respectively, with no significant differences in either group $(p=0.383)$ (Fig. 3B and C). The relative MFI of DCF fluorescence $12 \mathrm{~h}$ after ionizing irradiation without 5-ALA (RT $12 \mathrm{~h}$ ) $(1.41 \pm 0.13)$ was significantly higher than that in the RT $0 \mathrm{~h}$ group ( $\mathrm{p}=0.047)$ in the 9L cells. However, DCF fluorescence $12 \mathrm{~h}$ after ionizing irradiation with 5-ALA (1.91 \pm 0.19$)$ was obviously higher than that of the RT $12 \mathrm{~h}$ group $(\mathrm{p}=0.009)$. In the U251 cells, the relative MFI of DCF fluorescence in the 5-ALA without ionizing irradiation and in the RT $0 \mathrm{~h}$ group (means $\pm \mathrm{SE}$ ) was $0.87 \pm 0.06$ and $0.99 \pm 0.03$, respectively, with 

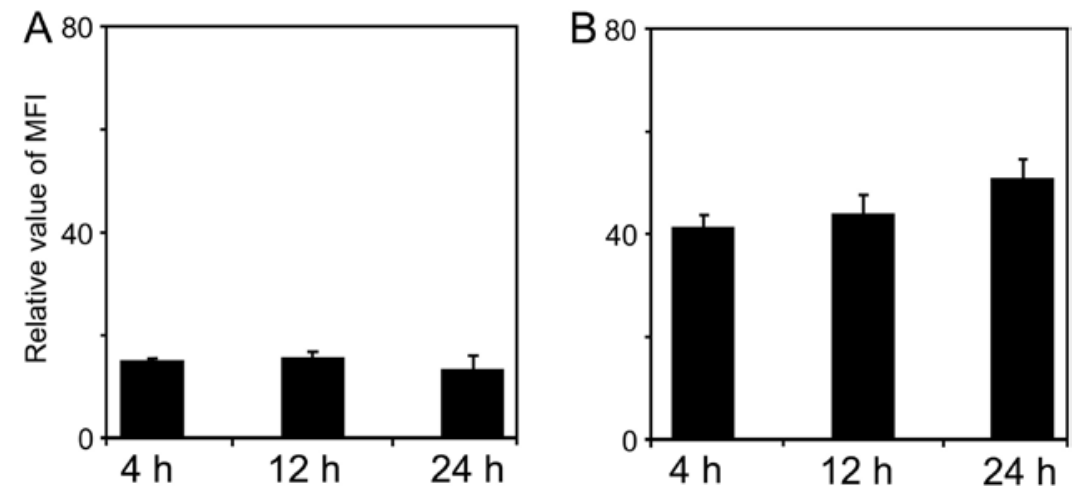

Figure 2. Temporal changes in the relative MFI of 5-ALA-induced PpIX fluorescence compared with the control 4, 12 and $24 \mathrm{~h}$ after ionizing irradiation in (A) 9L and (B) U251 cells. There were no significant differences among these groups in each cell line. Columns, mean ( $\mathrm{n}=3$ ); bars, SE. MFI, median fluorescence intensity; 5-ALA, 5-aminolevulinic acid; PpIX, protoporphyrin IX.
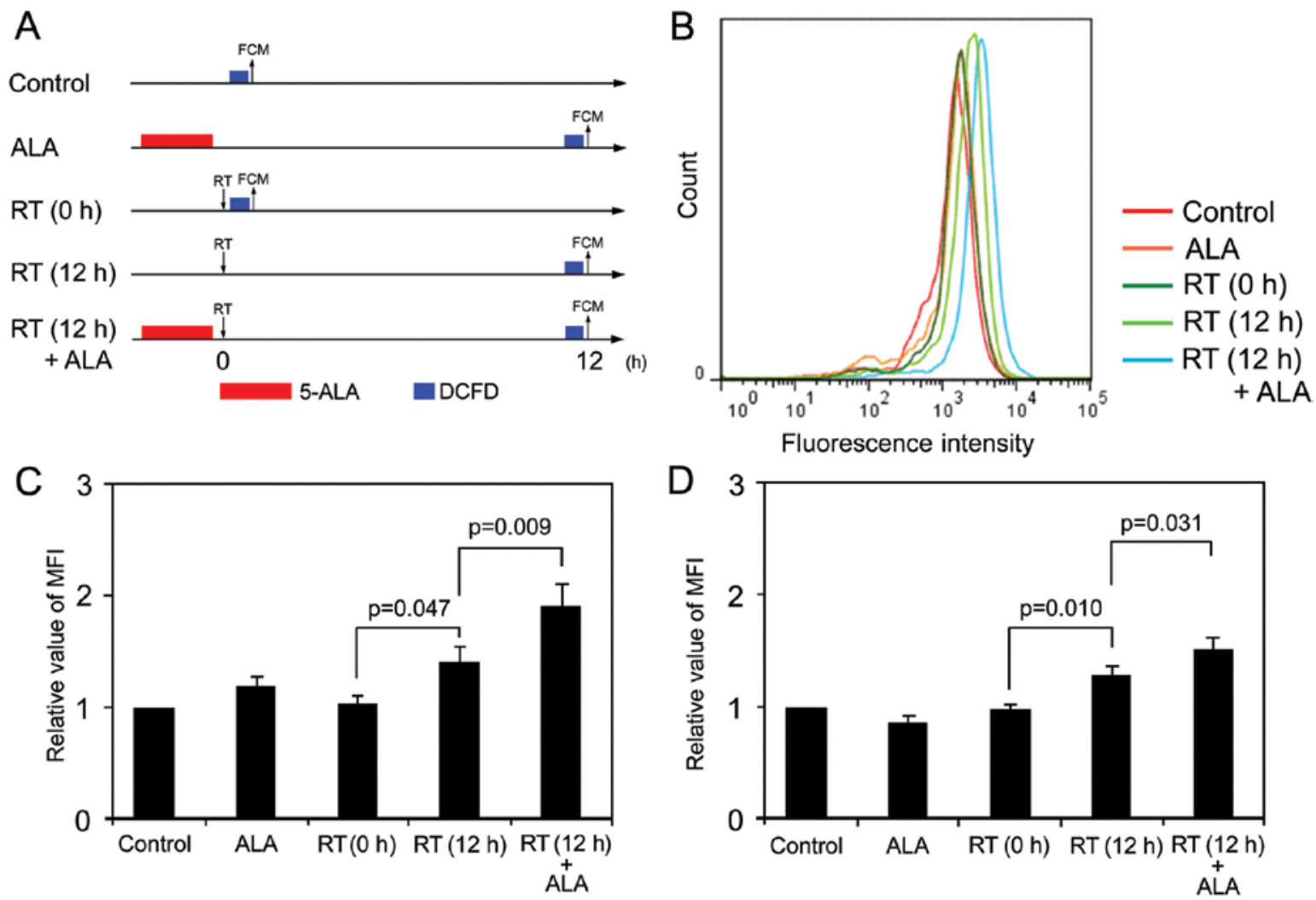

Figure 3. Intracellular production of reactive oxygen species (ROS) after ionizing irradiation in glioma cells using flow cytometric analyses. (A) Schedule of 5-ALA treatment, exposure of ionizing irradiation, and detection of ROS. Cells were incubated with $1 \mathrm{mM}$ 5-ALA for $4 \mathrm{~h}$. Detection of ROS was by an oxidant-sensitive fluorescent probe (DCFD). Control was the intracellular ROS levels in cells without 5-ALA treatment or exposure to ionizing irradiation. (B) Representative flow cytometric profiles of intracellular ROS levels in the 9L cells. Relative MFI of intracellular ROS levels after ionizing irradiation compared with the control in the (C) 9L and (D) U251 cells. ALA, treatment with only $1 \mathrm{mM} 5$-ALA; RT (0 h), cells just after ionizing irradiation but without 5-ALA treatment; RT $(12 \mathrm{~h})$, cells $12 \mathrm{~h}$ after ionizing irradiation but without 5-ALA treatment; RT $(12 \mathrm{~h})+$ ALA, cells $12 \mathrm{~h}$ after ionizing irradiation with 5-ALA pretreatment. Columns, mean $(\mathrm{n}=6)$; bars, SE. 5-ALA, 5-aminolevulinic acid; MFI, median fluorescent intensity.

no significant differences in either group ( $\mathrm{p}=0.262)$ (Fig. 3D). The relative MFI of DCF fluorescence in the RT $12 \mathrm{~h}$ group $(1.27 \pm 0.08)$ was significantly higher than that in the RT $0 \mathrm{~h}$ group ( $\mathrm{p}=0.011$ ). Similarly, DCF fluorescence $12 \mathrm{~h}$ after ionizing irradiation with 5-ALA (1.51 \pm 0.10$)$ was obviously higher than that in the RT $12 \mathrm{~h}$ group $(\mathrm{p}=0.031)$.

Delayed production of ROS in glioma cells after ionizing irradiation. Intracellular ROS after ionizing irradiation in the 9L and U251 cells were visualized by DCF fluorescence using the oxidant-sensitive probe DCFD according to our method (18) (Fig. 4). Previously, we confirmed no interaction between 5-ALA-induced PpIX and DCF fluorescence upon confocal laser scanning microscopy (18). DCF fluorescence was observed in the nucleus and cytoplasm $12 \mathrm{~h}$ after ionizing irradiation, with some differences in the intensity of DCF fluorescence among the cell lines (Fig. 4A-C in the 9L cells and Fig. 4G-I in the U251 cells). Conversely, pretreatment of 

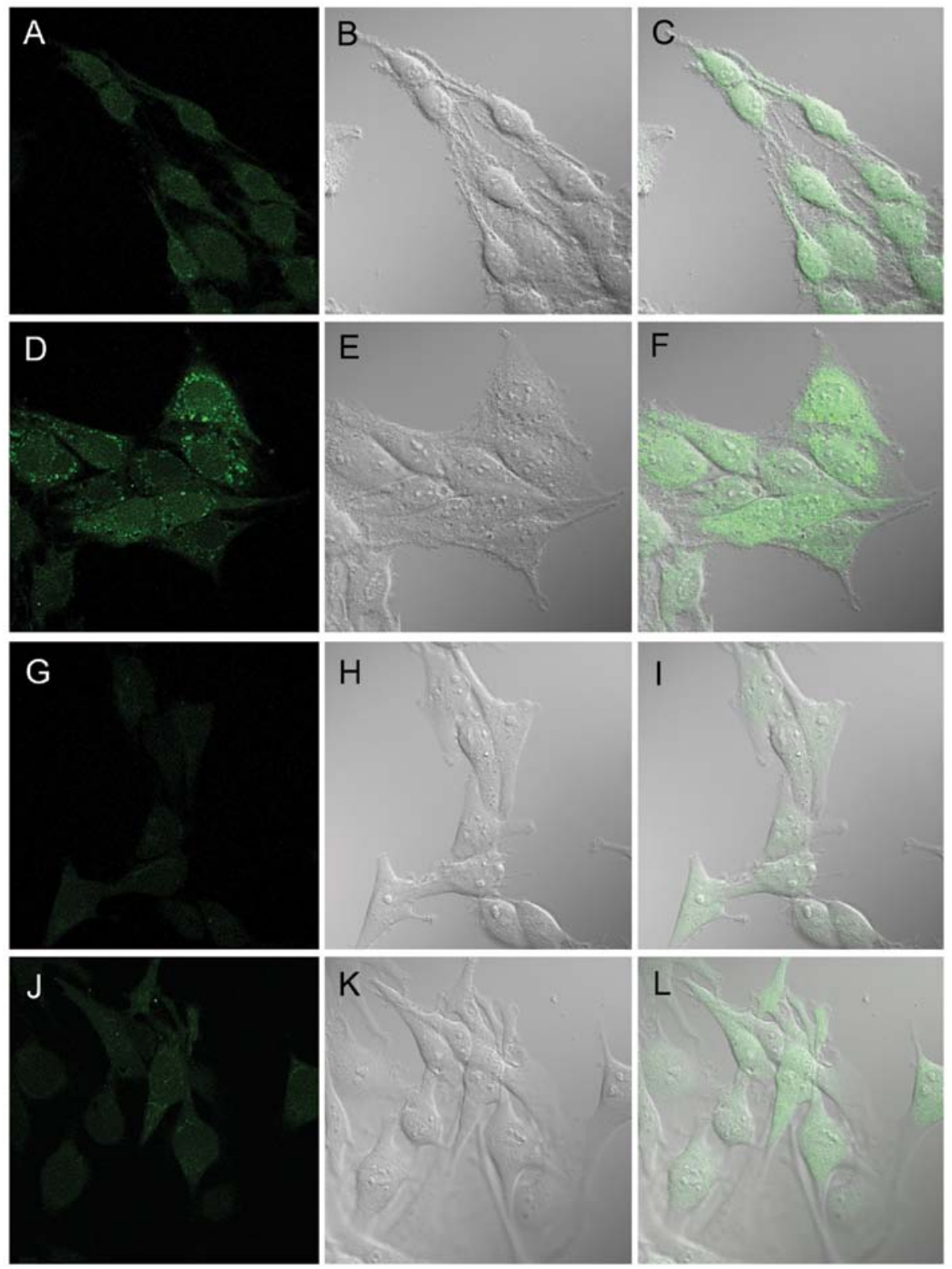

Figure 4. Visualization of intracellular ROS $12 \mathrm{~h}$ after ionizing irradiation in (A-F) 9L and (G-L) U251 cells. (A-C and G-I) Control cells were not treated with 5-ALA yet were exposed to ionizing irradiation (10 Gy). (D-F and J-L) Cells treated with $1 \mathrm{mM}$ 5-ALA and incubated for $4 \mathrm{~h}$, and then exposed to ionizing irradiation $(10 \mathrm{~Gy})$. Twelve hours after ionizing irradiation, all cells were treated with $10 \mu \mathrm{M}$ DCFD to identify intracellular ROS. (A, D, G and J) DCF fluorescence image. (B, E, H and K) DIC image. (C, F, I and L) Merged image corresponding to DCF fluorescence and DIC images. DCF fluorescence was observed in the nucleus and cytoplasm of control cells with different intensities in the cell lines (A-C and G-I). Notably, 5-ALA-pretreated cells had obviously increased DCF fluorescence, mainly in the cytoplasm of both cell lines (D-F and J-L). ROS, reactive oxygen species; 5-ALA, 5-aminolevulinic acid.

cells with 5-ALA before ionizing irradiation caused an obvious increase in DCF fluorescence, mainly in the cytoplasm of both cell lines (Fig. 4D-F and J-L).

Differences in timing of 5-ALA treatment influence delayed production of intracellular ROS after ionizing irradiation in glioma cells. To evaluate the influence of different timings of 5-ALA treatment upon delayed production of intracellular ROS, we employed three timings of 5-ALA treatment and evaluated ROS production $12 \mathrm{~h}$ after ionizing irradiation in each condition (Fig. 5A). In the 9L and U251 cells, DCF fluorescence of cells upon 5-ALA treatment just before ionizing irradiation [RT+ALA (pre) group] $(1.93 \pm 0.10$ in 9L cells, $1.44 \pm 0.02$ in U251 cells) was significantly higher than that in cells that underwent ionizing irradiation without 5-ALA treatment $(1.44 \pm 0.03$ in $9 \mathrm{~L}$ cells, $1.30 \pm 0.04$ in $\mathrm{U} 251$ cells $)$ $(\mathrm{p}=0.0009$ and 0.0135 , respectively), findings that were in agreement with the results of the previous experiment (Fig. 3). In the 9L cells, the DCF fluorescence of cells upon 5-ALA treatment just before ionizing irradiation [RT+ALA (pre) group] was significantly higher than that of the cells that underwent 5-ALA treatment just after ionizing irradiation [RT+ALA (4 h) group] $(1.57 \pm 0.05)$ and that of cells that underwent 5-ALA treatment $8 \mathrm{~h}$ after ionizing irradiation [RT+ALA $(12 \mathrm{~h})$ group] $(1.58 \pm 0.11)(\mathrm{p}=0.0072$ and 0.0078 , respectively) (Fig. 5B). The DCF fluorescence in the RT+ALA (pre) group in the U251 cells tended to be slightly higher compared with that of the $\mathrm{RT}+\mathrm{ALA}(4 \mathrm{~h})$ group $(1.43 \pm 0.02)$ and RT+ALA (12 h) group 


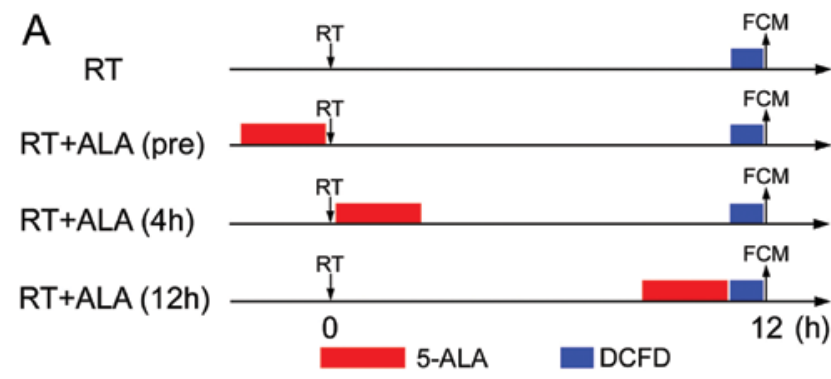

B

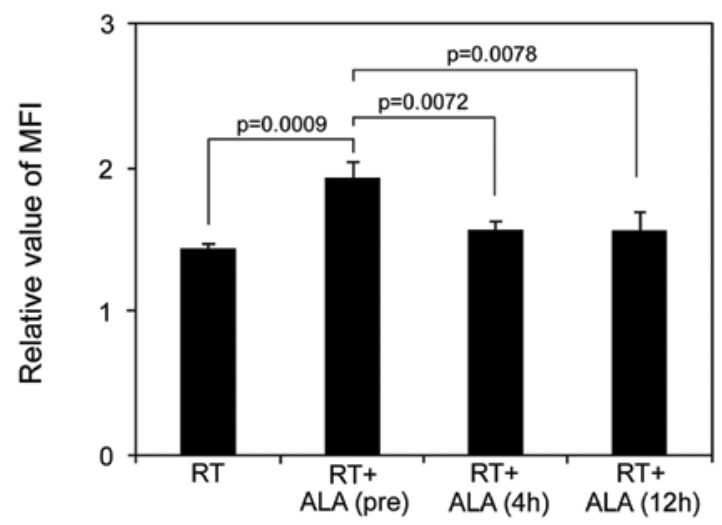

C

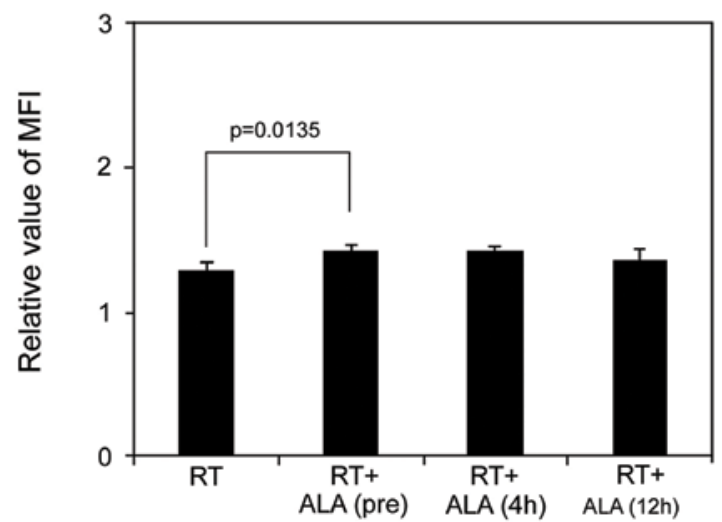

Figure 5. Effect of different timings of 5-ALA treatment on the intracellular production of reactive oxygen species (ROS) $12 \mathrm{~h}$ after ionizing irradiation in 9L and U251 cells using flow cytometric analyses and DCFD. (A) Schedule of different timings of 5-ALA treatment. (B) 9L and (C) U251 cells were treated with $1 \mathrm{mM}$ 5-ALA before, immediately after, and $8 \mathrm{~h}$ after ionizing irradiation. Intracellular levels of ROS were analyzed immediately after (pre), $4 \mathrm{~h}$ (4 h) and $12 \mathrm{~h} \mathrm{(12} \mathrm{h)} \mathrm{after} \mathrm{ionizing} \mathrm{irradiation.} \mathrm{Control} \mathrm{cells} \mathrm{did} \mathrm{not} \mathrm{undergo}$ 5-ALA treatment or exposure to ionizing irradiation. The relative MFI of the intracellular ROS levels compared with that of the control is shown. RT, only ionizing-irradiation exposure without 5-ALA treatment. RT+ALA (pre), cells pretreated with 5-ALA before ionizing irradiation; RT+ALA (4 h) group, cells treated with 5-ALA just after ionizing irradiation; RT+ALA (12 h), cells treated with 5-ALA at $8 \mathrm{~h}$ after ionizing irradiation. Columns, mean $(\mathrm{n}=3)$; bars, SE. 5-ALA, 5-aminolevulinic acid; MFI, median fluorescence intensity.

$(1.38 \pm 0.05)$, but the differences were not significant $(\mathrm{p}=0.7958$ and 0.2275 , respectively) (Fig. 5C).

\section{Discussion}

Ionizing irradiation has no influence on the synthesis of 5-ALA-induced PpIX in glioma cells. Previously, we demonstrated that multi-dose ionizing irradiation with repetitive administration of 5-ALA enhanced the radiosensitizing effect in glioma cells in vitro and in vivo, and that intracellular 5-ALA-induced PpIX increased intracellular levels of ROS generated by ionizing irradiation in glioma cells $(18,19)$. Before the present study, there had been only one report focusing on the synthesis of 5-ALA-induced PpIX in tumor cells after ionizing irradiation in vitro (17). Thus, to investigate the influence of the synthesis of 5-ALA-induced PpIX after ionizing irradiation, intracellular 5-ALA-induced PpIX at different intervals after ionizing irradiation was evaluated using flow cytometry in glioma cells in vitro. Our data demonstrated that the quantity of 5-ALA-induced PpIX produced after ionizing irradiation did not decrease in the glioma cells. Accordingly, ionizing irradiation did not influence the synthesis of 5-ALA induced-PpIX, and 5-ALA induced the accumulation of PpIX in glioma cells after exposure to ionizing irradiation, which is in agreement with a previous study (17). Therefore, we hypothesized that 5-ALA can operate upon tumor cells with several functions (including porphyrin synthesis in glioma cells) during and after exposure to ionizing irradiation.

Pretreatment with 5-ALA strongly increases delayed ROS production in the cytoplasm of glioma cells after ionizing irradiation. We demonstrated changes in intracellular production of ROS after ionizing irradiation quantitatively using flow cytometry. Intracellular ROS generated during ionizing irradiation, such as hydroxyl radicals, are unstable and disappear in $<10^{-3} \mathrm{sec}(20)$. Therefore, no increase in intracellular production of ROS just after ionizing irradiation was observed compared with the controls in both cell lines (Fig. 3). Conversely, intracellular production of ROS $12 \mathrm{~h}$ after ionizing irradiation was increased significantly compared with that just after ionizing irradiation in glioma cells, a finding that is in agreement with a recent study (25). In particular, pretreatment with 5-ALA obviously increased this delayed intracellular production of ROS after ionizing irradiation in glioma cells. We also confirmed the localization of delayed intracellular production of ROS after ionizing irradiation using confocal laser microscopy in vitro. Delayed production of ROS after ionizing irradiation was observed in the nucleus and cytoplasm with some differences between cell lines, but pretreatment with 5-ALA obviously enhanced intracellular production of ROS (mainly in the cytoplasm of glioma cells). This is the first study to demonstrate the quantitative evaluation of delayed intracellular production of ROS, as well as visualization of subcellular localization of these ROS after ionizing irradiation with 5-ALA in vitro.

5-ALA acts as a radiosensitizer via the enhancement of delayed ROS production in glioma. The mechanism of the radiosensitizing effect of 5-ALA-induced PpIX remains unclear. In general, ionizing irradiation induces tumor-cell death in two ways, i.e., radiation: i) is absorbed into the cell and interacts directly with DNA ('direct reaction'); ii) interacts with water to produce ROS (particularly hydroxyl radicals) that damage DNA and organelles (cell membrane, mitochondria) ("indirect reaction') and results in reproductive cell death $(21,29)$. These initial reactions during exposure to ionizing irradiation occur in a very short period (20). Recent studies have demonstrated that ionizing irradiation increases the membrane potential, respiration, and ATP production in mitochondria, and causes ROS production in the mitochondria of tumor cells $(24,25)$. These mitochondrial ROS are secondary products via a 
continual cascade of reactions initiated by the initial ROS (particularly hydroxyl radicals) (25,30-33). Importantly, these secondary metabolic processes occur about $12 \mathrm{~h}$ after ionizing irradiation, and induce long-lasting ROS production $(24,25)$. Moreover, these secondary ROS, long after ionizing irradiation, modify cellular molecules. Therefore, they have important roles in the responses to ionizing irradiation and cell signaling, causing cell death $(22,25,34)$. In general, mitochondrial respiratory activity is decreased in association with changes in the expression of cytochrome $c$ oxidase (COX) complex subunit proteins, causing a metabolic change called the 'Warburg effect' in tumor cells (35-38). The biological effect of administration of the heme precursor 5-ALA is not only high accumulation of PpIX within the mitochondria of tumor cells, but also generation of antitumor immunity via activation of heat-shock protein as well as inhibition of heme-oxygenase-1 with photoactivation and hyperthermia (26). Moreover, recent studies have reported that 5-ALA can improve the function of the mitochondrial respiratory chain (particularly COX activity) and thereby disrupt the Warburg effect and induce caspase-dependent apoptosis in tumor cells $(27,28)$. In our previous study, we demonstrated that multi-dose ionizing radiation induced strong aggregation of activated macrophages with phagocytic features within tumors, causing strong inhibition of tumor growth in glioma cells in vivo (19). Actually, real-time measurement of intracellular ROS is also technically difficult during exposure to ionizing irradiation. The present study demonstrated that 5-ALA obviously enhanced delayed ROS production in the cytoplasm of glioma cells after ionizing irradiation. Thus, 5-ALA enhances the long-lasting ROS production induced by secondary metabolic processes, and consequently acts as a radiosensitizer in glioma.

Possible mechanism of enhancement of delayed ROS production via 5-ALA with ionizing irradiation. The present study demonstrated that 5-ALA administration after ionizing irradiation tended to slightly increase delayed intracellular production of ROS. The direct biological effect of 5-ALA upon secondary production of ROS after ionizing irradiation may possibly be slight. Conversely, 5-ALA pretreatment before ionizing irradiation obviously enhanced these ROS in glioma cells compared with the other groups (Fig. 5). Although the type of free radicals associated with these ROS remains unclear, possible explanations of the enhancement of delayed production of intracellular ROS via 5-ALA with ionizing irradiation in glioma cells include: i) intracellular 5-ALA-induced PpIX may absorb the electron energy of ionizing irradiation and produce ROS; ii) 5-ALA induces high accumulation of PpIX within mitochondria and this PpIX may enhance formation of water-radiolysis products (mainly hydroxyl radicals) as initial ROS during ionizing irradiation in mitochondria; iii) 5-ALA increases the function of the mitochondrial respiratory chain and may enhance initial production of ROS in mitochondria during ionizing irradiation. Consequently, increased initial production of ROS may play an important role as a key mediator and lead to enhancement of delayed intracellular production of ROS via secondary metabolic processes in mitochondria. Further investigations on the biological effects of 5-ALA upon the mitochondrial respiratory chain under ionizing irradiation are required.
In conclusion, the present study demonstrated that 5-ALA can enhance delayed intracellular production of ROS after ionizing irradiation in glioma cells. Ionizing irradiation has no influence on the metabolic pathway of 5-ALA in glioma cells, whereas 5-ALA pretreatment before ionizing irradiation can obviously increase secondary production of ROS long after the ionizing irradiation. Therefore, multi-dose ionizing irradiation with repetitive administration of 5-ALA can enhance the radiosensitizing effect of 5-ALA in glioma via an increase in long-lasting ROS production generated by a secondary metabolic process.

\section{Acknowledgements}

The present study was supported by JSPS KAKENHI (grant no. 25462282).

\section{References}

1. Stupp R, Mason WP, van den Bent MJ, et al: Radiotherapy plus concomitant and adjuvant temozolomide for glioblastoma. N Engl J Med 352: 987-996, 2005.

2. Westphal M, Ram Z, Riddle V, Hilt D, Bortey E; Executive Committee of the Gliadel Study Group: Gliadel wafer in initial surgery for malignant glioma: long-term follow-up of a multicenter controlled trial. Acta Neurochir 148: 269-275, 2006.

3. Sanai N, Polley MY, McDermott MW, Parsa AT and Berger MS: An extent of resection threshold for newly diagnosed glioblastomas. J Neurosurg 115: 3-8, 2011.

4. Lacroix M, Abi-Said D, Fourney DR, et al: A multivariate analysis of 416 patients with glioblastoma multiforme: prognosis, extent of resection, and survival. J Neurosurg 95: 190-198, 2001.

5. Fischer F, Dickson EF, Kennedy JC and Pottier RH: An affordable, portable fluorescence imaging device for skin lesion detection using a dual wavelength approach for image contrast enhancement and aminolaevulinic acid-induced protoporphyrin IX. Part II. In vivo testing. Lasers Med Sci 16: 207-212, 2001.

6. Yamamoto J, Yamamoto S, Hirano $\mathrm{T}$, et al: Monitoring of singlet oxygen is useful for predicting the photodynamic effects in the treatment for experimental glioma. Clin Cancer Res 12: 7132-7139, 2006.

7. Stummer W, Novotny A, Stepp H, Goetz C, Bise K and Reulen HJ: Fluorescence-guided resection of glioblastoma multiforme by using 5-aminolevulinic acid-induced porphyrins: a prospective study in 52 consecutive patients. J Neurosurg 93: 1003-1013, 2000.

8. Tamura Y, Kuroiwa T, Kajimoto Y, Miki Y, Miyatake S and Tsuji M: Endoscopic identification and biopsy sampling of an intraventricular malignant glioma using a 5-aminolevulinic acid-induced protoporphyrin IX fluorescence imaging system. Technical note. J Neurosurg 106: 507-510, 2007.

9. Della Puppa A, De Pellegrin S, d'Avella E, et al: 5-aminolevulinic acid (5-ALA) fluorescence guided surgery of high-grade gliomas in eloquent areas assisted by functional mapping. Our experience and review of the literature. Acta Neurochir 155: 965-972, 2013.

10. Shapiro WR, Green SB, Burger PC, et al: Randomized trial of three chemotherapy regimens and two radiotherapy regimens and two radiotherapy regimens in postoperative treatment of malignant glioma. Brain Tumor Cooperative Group Trial 8001. J Neurosurg 71: 1-9, 1989.

11. Laperriere N, Zuraw L, Cairncross G; Cancer Care Ontario Practice Guidelines Initiative Neuro-Oncology Disease Site Group: Radiotherapy for newly diagnosed malignant glioma in adults: a systematic review. Radiother Oncol 64: 259-273, 2002.

12. Mimura S, Ito Y, Nagayo T, et al: Cooperative clinical trial of photodynamic therapy with photofrin II and excimer dye laser for early gastric cancer. Lasers Surg Med 19: 168-172, 1996.

13. Mlkvy P, Messmann H, Pauer M, et al: Distribution and photodynamic effects of meso-tetrahydroxyphenylchlorin (mTHPC) in the pancreas and adjacent tissues in the Syrian golden hamster. Br J Cancer 73: 1473-1479, 1996. 
14. Yamamoto J, Hirano T, Li S, et al: Selective accumulation and strong photodynamic effects of a new photosensitizer, ATX-S10. $\mathrm{Na}$ (II), in experimental malignant glioma. Int J Oncol 27: $1207-1213,2005$

15. Schaffer M, Ertl-Wagner B, Schaffer PM, et al: Feasibility of photofrin II as a radiosensitizing agent in solid tumors - preliminary results. Onkologie 29: 514-519, 2006.

16. Luksiene Z, Juzenas P and Moan J: Radiosensitization of tumours by porphyrins. Cancer Lett 235: 40-47, 2006.

17. Berg K, Luksiene Z, Moan J and Ma L: Combined treatment of ionizing radiation and photosensitization by 5 -aminolevulinic acid-induced protoporphyrin IX. Radiat Res 142: 340-346, 1995

18. Yamamoto J, Ogura S, Tanaka T, et al: Radiosensitizing effect of 5-aminolevulinic acid-induced protoporphyrin IX in glioma cells in vitro. Oncol Rep 27: 1748-1752, 2012.

19. Yamamoto J, Ogura S, Shimajiri S, et al: 5-Aminolevulinic acid-induced protoporphyrin IX with multi-dose ionizing irradiation enhances host antitumor response and strongly inhibits tumor growth in experimental glioma in vivo. Mol Med Rep (In press).

20. Riley PA: Free radicals in biology: oxidative stress and the effects of ionizing radiation. Int J Radiat Biol 65: 27-33, 1994.

21. Hall EJ and Giaccia AJ: Physics and chemistry of radiation absorption. In: Radiobiology for the Radiologist. Hall EJ and Giaccia AJ (eds). 6th edition. Lippincott Williams \& Wilkins, Philadelphia, PA, pp5-15, 2006.

22. Chen Q, Chai YC, Mazumder S, et al: The late increase in intracellular free radical oxygen species during apoptosis is associated with cytochrome $c$ release, caspase activation, and mitochondrial dysfunction. Cell Death Differ 10: 323-334, 2003.

23. Ogura A, Oowada S, Kon Y, et al: Redox regulation in radiationinduced cytochrome $c$ release from mitochondria of human lung carcinoma A549 cells. Cancer Lett 277: 64-71, 2009.

24. Saenko Y, Cieslar-Pobuda A, Skonieczna M and RzeszowskaWolny J: Changes of reactive oxygen and nitrogen species and mitochondrial functioning in human K562 and HL60 cells exposed to ionizing radiation. Radiat Res 180: 360-366, 2013.

25. Yamamori $\mathrm{T}$, Yasui $\mathrm{H}$, Yamazumi $\mathrm{M}$, et al: Ionizing radiation induces mitochondrial reactive oxygen species production accompanied by upregulation of mitochondrial electron transport chain function and mitochondrial content under control of the cell cycle checkpoint. Free Radic Biol Med 53: 260-270, 2012.
26. Ishizuka M, Abe F, Sano Y, et al: Novel development of 5-aminolevurinic acid (ALA) in cancer diagnoses and therapy. Int Immunopharmacol 11: 358-365, 2011.

27. Ogura S, Maruyama K, Hagiya Y, et al: The effect of 5-aminolevulinic acid on cytochrome $c$ oxidase activity in mouse liver. BMC Res Notes 4: 66, 2011.

28. Sugiyama Y, Hagiya Y, Nakajima M, Ishizuka M, Tanaka T and Ogura S: The heme precursor 5-aminolevulinic acid disrupts the Warburg effect in tumor cells and induces caspase-dependent apoptosis. Oncol Rep 31: 1282-1286, 2014.

29. Hosokawa Y, Sakakura Y, Tanaka L, Okumura K, Yajima T and Kaneko M: Radiation-induced apoptosis is independent of caspase- 8 but dependent on cytochrome $c$ and the caspase- 9 cascade in human leukemia HL60 cells. J Radiat Res 46: 293-303, 2005.

30. Kowaltowski AJ, de Souza-Pinto NC, Castilho RF and Vercesi AE: Mitochondria and reactive oxygen species. Free Radic Biol Med 47: 333-343, 2009.

31. Le Caër S: Water radiolysis: influence of oxide surfaces on $\mathrm{H}_{2}$ production under ionizing radiation. Water 3: 235-253, 2011.

32. Wallace SS: Enzymatic processing of radiation-induced free radical damage in DNA. Radiat Res 150 (Suppl 5): S60-S79, 1998.

33. Ward JF: DNA damage produced by ionizing radiation in mammalian cells: identities, mechanisms of formation, and reparability. Prog Nucleic Acid Res Mol Biol 35: 95-125, 1988.

34. Finkel T: Signal transduction by reactive oxygen species. J Cell Biol 194: 7-15, 2011

35. Matoba S, Kang JG, Patino WD, et al: p53 regulates mitochondrial respiration. Science 312: 1650-1653, 2006.

36. Herrmann PC, Gillespie JW, Charboneau L, et al: Mitochondrial proteome: altered cytochrome $c$ oxidase subunit levels in prostate cancer. Proteomics 3: 1801-1810, 2003.

37. Zhou S, Kachhap S and Singh KK: Mitochondrial impairment in p53-deficient human cancer cells. Mutagenesis 18: 287-292, 2003.

38. Warburg O: On respiratory impairment in cancer cells. Science 124: 269-270, 1956. 